\title{
MANAJEMEN LABA MENGGUNAKAN CLASSIFICATION SHIFTING DAN KUALITAS AUDIT
}

\author{
Debbianita \\ Prodi Akuntansi Fakultas Ekonomi Universitas Kristen Maranatha \\ Jl. Prof. Drg. Suria Sumantri No.65 Bandung, 40164, Indonesia \\ Sylvia Veronica Siregar dan Desi Adhariani \\ Program Pascasarjana Ilmu Akuntansi, Fakultas Ekonomi dan Bisnis, Universitas Indonesia \\ Kampus UI, Depok, 16424
}

\begin{abstract}
This research aims to detect earnings management through classification shifting by classifying core expenses as discontinued operation or special items to increase core earnings. This research also predict that Audit Quality (KAP big 4 or non-big 4) can mitigate earnings management through classification shifting. Samples of this research are obtained by using purposive sampling from all companies listed in the capital markets of Singapore, Malaysia, Indonesia, and Philippines. Methods of data analysis used in this research were multiple linear regression cross section data were processed using statistical software E-views 6.0. Final samples are 1551 observations for the year 2012. Results showed that there no classification shifting through discontinued operations and special items. Audit Quality is found to be unable to mitigate earnings management through classification shifting.
\end{abstract}

Keywords: Classification shifting, discontinued operations, special items, audit quality.

\section{PENDAHULUAN}

Laporan keuangan merupakan sarana yang menggambarkan kondisi keuangan perusahaan dan menjadi sarana informasi dari pihak dalam perusahaan (manajemen) kepada pihak-pihak di luar perusahaan. Laporan keuangan ini sangat penting bagi investor, terutama sebagai dasar untuk peng- ambilan keputusan investasi. Salah satu aspek penting dalam laporan keuangan adalah angka laba, yang sering menjadi pusat perhatian dari para pengguna laporan keuangan. Angka laba digunakan sebagai indikator kinerja pihak manajemen dalam mengelola kekayaan perusahaan, karena pentingnya angka laba tersebut maka memunculkan perilaku opportunistik dari manajemen untuk melakukan

Korespondensi dengan Penulis:

Debbianita: Telp. +62 222012168 Ext.1528; Fax. +62 2220127625

Email: debbianita@gmail.com 
manipulasi terhadap angka laba yang akan dilaporkan dalam laporan keuangan. Manajemen termotivasi untuk menunjukkan kinerja yang baik melalui nilai atau keuntungan yang diperoleh perusahaan, oleh karena itu manajemen cenderung untuk memilih dan menerapkan metode akuntansi yang dapat memberikan informasi laba yang lebih baik.

Terdapat dua alat manajemen laba yang dikenal luas di masyarakat yaitu manajemen akrual dan manipulasi aktivitas riil, namun kedua alat manajemen laba tersebut sudah banyak diketahui oleh para pengguna laporan keuangan dan sudah banyak dibahas dalam penelitian. Terdapat sebuah alat manajemen laba lainnya yaitu classification shifting yang berbeda dengan kedua alat manajemen laba yang sebelumnya yaitu classification shifting mengelola laba dengan secara sengaja menggeser klasifikasi item-item dalam laporan laba/rugi (Mc Vay, 2006).

Classification shifting seringkali tidak menjadi perhatian para pengguna laporan keuangan karena para pengguna laporan keuangan umumnya fokus pada core earnings sedangkan classification shifting tidak mengubah laba bersih tetapi hanya menggeser klasifikasinya agar core earnings yang dilaporkan meningkat.

Kesalahan klasifikasi yang dilakukan manajemen seharusnya dapat dideteksi oleh auditor. Peran auditor sangat penting untuk mengurangi atau menghambat kemungkinan adanya manajemen laba yang terjadi. Menurut Herusetya (2012), auditor memiliki peran sebagai salah satu gatekeeper pasar modal untuk memberikan kepastian (assurance) atas kualitas pelaporan keuangan perusahaan publik.

Pemilihan negara ASEAN sebagai sampel dalam penelitian ini dilakukan mengingat pada akhir tahun 2015 akan diwujudkan ASEAN Economic Community (AEC) yang akan memberi kesempatan bagi masing-masing negara untuk bertumbuh dan mengembangkan negaranya.
Penelitian-penelitian mengenai classification shifting masih jarang apabila dibandingkan dengan penelitian manajemen akrual dan manipulasi aktivitas riil, terutama di Indonesia masih jarang sekali penelitian yang mengangkat tema classification shifting. Penelitian yang mengembangkan model untuk pengukuran classification shifting adalah penelitian Mc Vay (2006) yang melakukan pengujian antara core earnings dan special items, hasil penelitiannya memberikan bukti adanya perilaku opportunistik manajer yang melakukan classification shifting dengan menggeser core expense (harga pokok penjualan, biaya penjualan, serta biaya umum dan administrasi) ke special items. Untuk memastikan bahwa peningkatan core earnings diakibatkan karena adanya classification shifting dan bukan dikarenakan perusahaan mengalami efficiency gains, dilakukan pengujian apakah adanya special items tahun ini menurunkan unexpected core earnings tahun berikutnya. Hasil penelitian membuktikan bahwa special items pada tahun $t$ memiliki pengaruh negatif terhadap unexpected change in core earnings pada $t+1$ yang berarti peningkatan unexpected core earnings dikarenakan adanya classification shifting.

Sejak penelitian Mc Vay (2006), penelitian classification shifting semakin banyak antara lain penelitian Fan et al. (2010) yang mengembangkan model Mc Vay tetapi dengan mengeluarkan variabel akrual dan menambahkan variabel kontrol seperti return dan $_{\mathrm{t}}$ return $_{\mathrm{t}+1}$ serta menggunakan data keuangan kuartalan. Hasil penelitian Fan et al. (2010) menemukan bahwa manajer lebih cenderung melakukan classification shifting pada kuartal keempat, dengan argumen pada kuartal keempat ini proses audit difokuskan sehingga dengan penggunaan classification shifting tidak terdeteksi oleh auditor. Barua et al. (2010) mencoba meneliti classification shifting menggunakan core earnings dan operasi yang dihentikan. Hasilnya ditemukan bahwa terdapat perilaku manajemen yang menggeser core expense ke operasi yang dihentikan untuk meningkatkan core earnings. Penelitian classification shifting 


\section{Jurnal Keuangan dan Perbankan | KEUANGAN}

Vol. 20, No.2, Mei 2016: 186- 194

di Indonesia dilakukan oleh Wulandari dan Kusuma (2011) menggunakan data keuangan negara-negara di ASEAN, penelitian ini menguji core earnings dan pos-pos luar biasa dan hasilnya tidak menunjukkan adanya classification shifting yang dilakukan oleh para manajer.

\section{Hipotesis}

H1a : Operasi yang dihentikan berpengaruh positif terhadap unexpected core earnings.

$\mathrm{H} 1 \mathrm{~b}$ : Special items berpengaruh positif terhadap unexpected core earnings.

$\mathrm{H} 2 \mathrm{a}$ : Operasi yang dihentikan tahun ini berpengaruh negatif terhadap unexpected change in core earnings tahun berikutnya.

$\mathrm{H} 2 \mathrm{~b}$ : Special items tahun ini berpengaruh negatif terhadap unexpected change in core earnings tahun berikutnya.

H3a : Pengaruh positif operasi yang dihentikan terhadap unexpected core earnings akan lebih kecil pada perusahaan yang diaudit oleh KAP big 4 dibandingkan dengan perusahaan yang diaudit oleh KAP non-big 4.

$\mathrm{H} 3 \mathrm{~b}$ : Pengaruh positif special items terhadap unexpected core earnings akan lebih kecil pada perusahaan yang diaudit oleh KAP big 4 dibandingkan dengan perusahaan yang diaudit oleh KAP non-big 4.

H4a : Pengaruh negatif operasi yang dihentikan tahun ini terhadap unexpected change in core earnings tahun berikutnya akan lebih kecil pada perusahaan yang diaudit oleh KAP big 4 dibandingkan dengan perusahaan yang diaudit oleh KAP non-big 4.

$\mathrm{H} 4 \mathrm{~b}$ : Pengaruh negatif special items tahun ini terhadap unexpected change in coreearnings tahun berikutnya akan lebih kecil pada perusahaan yang diaudit oleh KAP big 4 dibandingkan dengan perusahaan yang diaudit oleh KAP non-big 4.

\section{METODE}

Penelitian ini menggunakan data kuantitatif dan sumber data yang digunakan berupa data sekunder, yaitu laporan keuangan perusahaan-perusahaan yang terdaftar di bursa saham Indonesia, Malaysia, Singapura, dan Filipina tahun 2011 sampai 2013, karena penelitian ini membutuhkan 1 tahun dari data lead dan 1 tahun dari data lag. Data laporan keuangan diambil dari Thomson Reuters Datastream dan eikon Pusat Data Ekonomi dan Bisnis Universitas Indonesia.

\section{a. Operasionalisasi Variabel}

- Variabel Dependen

a. Unexpected Core Earnings

$$
U E_{-} C E_{t}=\text { reported } C E_{t}-\text { predicted } C E_{t}
$$

Predicted $C E_{t}$ adalah core earnings prediksian dalam tahun $t$, yaitu nilai prediksi dihitung menggunakan predicted value dari persamaan (1) yang diestimasi berdasarkan tahun dan industri (Mc Vay, 2006).

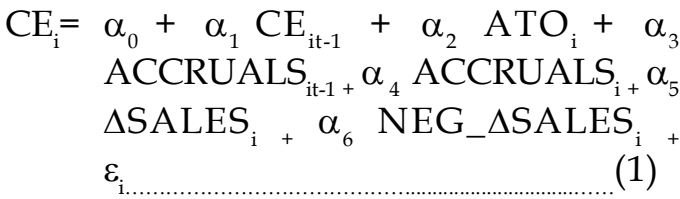

b. Unexpected Change in Core Earnings

$U E \_\Delta C E_{t+1}=$ reported $\Delta C E_{t+1}-$ predicted $\Delta C E_{t+1}$

Predicted $\triangle C E_{i}$ adalah perubahan core earnings prediksian perusahaan $i$ dari tahun $t$ ke $t+1$ dihitung menggunakan predicted value dari persamaan (2) yang diambil dari persamaan Mc Vay (2006). Persamaan (2) digunakan untuk menguji tahun $t+1$.

$$
\begin{aligned}
& \ddot{A} \mathrm{CE}_{\mathrm{i}}=\alpha_{0}+\alpha_{1} \mathrm{CE}_{\mathrm{it}-1}+\alpha_{2} \Delta \mathrm{CE}_{\mathrm{it}-1}+\alpha_{3} \Delta \mathrm{ATO}_{\mathrm{i}} \\
& +\alpha_{4} \text { ACCRUALS }_{\mathrm{it}-1}+\alpha_{5} \\
& \text { ACCRUALS }_{i}+\alpha_{6} \Delta \text { SALES }_{i}+\alpha_{7} \\
& N_{E G} \Delta \text { SALES }_{\mathrm{i}}+\gamma_{\mathrm{i}}
\end{aligned}
$$


- Variabel Independen

a. Operasi yang dihentikan (Discontinued Operations/ $\mathrm{Do}_{\mathrm{i}}$ )

$D O_{i}=$ Discontinued Operations $_{i}{ }^{*}(-1) /$ Sales

b. Special items $\left(\mathrm{SI}_{\mathrm{i}}\right)$

$S I_{i}=$ Special Items $_{i}{ }^{*}(-1) /$ Sales

- Variabel Moderasi

Audit Quality

Proksi yang digunakan untuk mengukur kualitas audit adalah ukuran KAP yang dibedakan menjadi KAP big 4 dan non-big 4 (Tendeloo dan Vanstraelen, 2008).

- Variabel Kontrol

Dalam penelitian ini digunakan beberapa variabel kontrol seperti yang digunakan oleh Barua et al (2010), yaitu ukuran perusahaan (SIZE $\mathrm{E}_{\mathrm{i}}$ ), rasio Book Value to Market Value $\left(\mathrm{BM}_{\mathrm{i}}\right)$, operating accruals (ACCRUALS $)$, return on asset $\left(\mathrm{ROA}_{\mathrm{i}}\right)$, dan operating cash flow $\left(\mathrm{OCF}_{\mathrm{i}}\right)$

- Variabel Lintas Negara/Country Characteristics

a. Per Capita Gross Domestic Product Growth $\left(\mathrm{GDP}_{\mathrm{i}}\right)$

b. Investment Protection $\left(\mathrm{INV}_{\mathrm{i}}\right)$

\section{b. Model Penelitian}

- Pengujian Hipotesis 1

$\mathrm{UE} \_\mathrm{CE}_{\mathrm{i}}=\varphi_{0}+\varphi_{1} \mathrm{DO}_{\mathrm{i}}+\varphi_{2} \mathrm{SI}_{\mathrm{i}}+\varphi_{3} \mathrm{SIZE}_{\mathrm{i}}+$ $\varphi_{4} \mathrm{BM}_{\mathrm{i}}+\varphi_{5} \mathrm{ACCRUALS}_{\mathrm{i}}+\varphi_{6} \mathrm{ROA}_{\mathrm{i}}+\varphi_{7} \mathrm{OCF}_{\mathrm{i}}$

$+\varphi_{8} \mathrm{GDP}_{\mathrm{i}}+\varphi_{9} \mathrm{DINV}_{\mathrm{i}}+\varepsilon_{\mathrm{i}}$

- Pengujian Hipotesis 2

UE_ $\Delta C E_{\mathrm{it}+1}=\eta_{0}+\eta_{1} \mathrm{DO}_{\mathrm{i}}+\eta_{2} \mathrm{SI}_{\mathrm{i}}+\eta_{3} \mathrm{SIZE}_{\mathrm{i}}+$ $\eta_{4} \mathrm{BM}_{\mathrm{i}}+\eta_{5}$ ACCRUALS $_{\mathrm{i}}+\eta_{6} \mathrm{ROA}_{\mathrm{i}}+\eta_{7} \mathrm{OCF}_{\mathrm{i}}$

$+\eta_{8} \mathrm{GDP}_{\mathrm{i}}+\eta_{9} \mathrm{DINV}+\varepsilon_{\mathrm{it}+1}$
- Pengujian Hipotesis 3

$$
\begin{aligned}
& \mathrm{UE} \_\mathrm{CE}_{\mathrm{i}}=\lambda_{0}+\lambda_{1} \mathrm{DO}_{\mathrm{i}}+\lambda_{2} \mathrm{SI}_{\mathrm{i}}+\lambda_{3} \mathrm{DO}_{\mathrm{it}}{ }^{*} \mathrm{DKAP}_{\mathrm{i}} \\
& +\lambda_{4} \mathrm{SI}_{\mathrm{it}}{ }^{*} \mathrm{DKAP}_{\mathrm{i}}+\lambda_{5} \mathrm{SIZE}_{\mathrm{i}}+\lambda_{6} \mathrm{BM}_{\mathrm{i}}+\lambda_{7} \\
& \text { ACCRUALS }_{i}+\lambda_{8} \text { ROA }_{i}+\lambda_{9} \mathrm{OCF}_{\mathrm{i}}++\lambda_{10} \\
& \mathrm{GDP}_{\mathrm{i}}+\lambda_{11} \mathrm{DINV}_{\mathrm{i}}+\varepsilon_{\mathrm{i}}
\end{aligned}
$$

- Pengujian Hipotesis 4

$$
\begin{aligned}
& \mathrm{UE}_{-} \mathrm{CE}_{\mathrm{it}+1}=\delta_{0}+\delta_{1} \mathrm{DO}_{\mathrm{i}}+\delta_{2} \mathrm{SI}_{\mathrm{i}}+\delta_{3} \\
& \mathrm{DO}_{\mathrm{it}}^{*} \mathrm{DKAP}_{\mathrm{i}}+\delta_{4} \mathrm{SI}_{\mathrm{it}}^{*} \mathrm{DKAP}_{\mathrm{i}}+\delta_{5} \mathrm{SIZE}_{\mathrm{i}}+\delta_{6} \\
& \mathrm{BM}_{\mathrm{i}}+\delta_{7} \mathrm{ACCRUALS}_{\mathrm{i}}+\delta_{8} \mathrm{ROA}_{\mathrm{i}}+\delta_{9} \mathrm{OCF}_{\mathrm{i}}+ \\
& \delta_{10} \mathrm{GDP}_{\mathrm{i}}+\delta_{11} \mathrm{DINV}_{\mathrm{i}}+\varepsilon_{\mathrm{i}} \ldots \ldots \ldots \ldots \ldots \ldots
\end{aligned}
$$

HASIL

\section{Statistik Deskriptif}

Sampel akhir yang digunakan dalam penelitian ini berjumlah 1.551 observasi. Statistik deskriptif variabel UE_ $\Delta$ CE menunjukkan bahwa sebagian besar perusahaan mengalami penurunan unexpected core earnings. Dari variabel UE_CE dapat dikatakan bahwa sebagian besar perusahaan memiliki unexpected core earnings yang positif yang berarti bahwa core earnings yang dilaporkan perusahaan lebih besar dibandingkan dengan predicted core earnings. Hal tersebut berarti investor melakukan kesalahan dalam menganalisis laporan keuangan, dan dapat dimungkinan adanya indikasi manajemen laba sehingga prediksi investor tidak tepat. Perusahaanperusahaan yang dijadikan sampel dalam penelitian ini melaporkan 2 jenis operasi yang dihentikan yaitu laba dari operasi yang dihentikan maupun kerugian akibat operasi yang dihentikan. Demikian juga variabel special items yang dilaporkan perusahaan-perusahaan yang menjadi sampel dalam penelitian ini adalah special item negatif dan positif.

Dari variabel DKAP dan DINV dapat dikatakan bahwa sebagian besar sampel yang digunakan dalam penelitian ini menggunakan KAP nonbig 4, hanya negara Singapura yang di dominasi oleh KAP big 4. Untuk DINV, mayoritas sampel dalan penelitian ini merupakan negara common law yang memiliki peraturan lebih baik dalam melindungi investornya sehingga insentif manajemen 
untuk melakukan classification shifting lebih kecil karena negara memberikan proteksi yang lebih kuat terhadap investor. Dalam Wardhani (2009), negara Indonesia dan Filiphina termasuk ke dalam kategori civil law sedangkan negara Singapura dan Malaysia dikategorikan sebagai negara common law.

\section{- Hasil Pengujian Hipotesis 1}

Berdasarkan hasil analisis regresi diperoleh kesimpulan hipotesis 1a ditolak yang dilihat dari $p$-value yang signifikan pada level 5\% tetapi memberikan koefisien negatif sehingga dapat diartikan bahwa operasi yang dihentikan memiliki pengaruh negatif terhadap unexpected core earnings.

\section{- $\quad$ Hasil Pengujian Hipotesis 2}

Hasil pengujian hipotesis $2 a$ dan $2 b$ tidak sesuai dengan prediksi awal, hal ini memperkuat hasil pengujian hipotesis 1 bahwa tidak terjadi manajemen laba melalui classification shifting dengan menggeser core expense ke operasi yang dihentikan dan special items.

Tabel 1. Statistik Deskriptif

\begin{tabular}{lcrrrrr}
\hline \multicolumn{1}{c}{ Variabel } & $\mathbf{n}$ & \multicolumn{1}{c}{ Mean } & \multicolumn{1}{c}{ Median } & \multicolumn{1}{c}{ Std Dev } & \multicolumn{1}{c}{ Min } & \multicolumn{1}{c}{ Max } \\
\hline UE_ACE & 1551 & -0.0014 & -0.0011 & 0.1917 & -1.6475 & 1.2100 \\
UE_CE & 1551 & 0.0000 & 0.0084 & 0.2016 & -1.9080 & 1.0231 \\
DO & 1551 & 0.1085 & 0.0000 & 2.9810 & -12.046 & 93.5000 \\
SI & 1551 & -0.0138 & 0.0000 & 0.1208 & -0.8333 & 0.3921 \\
SIZE (dalam US\$) & 1551 & 142,902 & 123,875 & 6.0000 & 1.0000 & $63,097,368$ \\
ROA & 1551 & 8.2943 & 4.4500 & 216.3693 & -1030.5400 & 8433.68 \\
BM & 1551 & 1.3787 & 1.0526 & 3.2612 & -25.0000 & 100.0000 \\
ACRUAL & 1551 & 0.3855 & -0.0282 & 14.3362 & -143.0173 & 413.3333 \\
OCF & 1551 & 0.0647 & 0.0520 & 1.1304 & -21.5000 & 29.3282 \\
GDP (dalam milyar US\$) & 1551 & 398.000 & 305.000 & 228.0000 & 250.0000 & 877.0000 \\
\hline
\end{tabular}

Tabel 2. Hasil Pengujian Hipotesis 1

\begin{tabular}{cccccccc}
\hline Var & Prediksi & Coefficient & Prob. & Variabel & Prediksi & Coefficient & \multicolumn{1}{c}{ Prob. } \\
\hline C & & 1.0080 & 0.0235 & ACCRUAL & + & 0.0014 & 0.4775 \\
DO & H1a: + & -2.1295 & $0.0339^{* *}$ & ROA & - & 0.0041 & $0.0000^{* * *}$ \\
SI & H1b: + & 0.0710 & 0.2462 & OCF & + & 0.0655 & 0.1251 \\
SIZE & - & 0.0022 & 0.2078 & GDP & - & -0.0383 & $0.0183^{* *}$ \\
BM & + & 0.0024 & 0.2722 & DINV & - & -0.0436 & $0.0126^{* *}$ \\
\hline R-squared & & & & & & 0.1472 \\
\multicolumn{2}{l}{ Adjusted Rsquared } & & & & & & 0.1422 \\
\multicolumn{2}{l}{ Prob(F-statistic) } & & & & & & $0.0000^{* * *}$ \\
\hline
\end{tabular}




\section{Hasil Pengujian Hipotesis 3}

Berdasarkan hasil regresi, hipotesis 3 baik 3a maupun $3 b$ ditolak karena $p$-value $>10 \%$, hal ini berarti bahwa kualitas audit tidak terbukti dapat mengurangi/menghambat terjadinya classification shifting. Hasil ini kemungkinan dikarenakan hasil pengujian hipotesis sebelumnya tidak terbukti ditemukan adanya classification shifting sehingga pengujian $\mathrm{H} 3$ tidak dapat membuktikan pengaruh kualitas audit terhadap classification shifting.

Tabel 3. Hasil Pengujian Hipotesis 2

\begin{tabular}{cccccccc}
\hline Variabel & Prediksi & Coefficient & \multicolumn{1}{c}{ Prob. } & Variabel & Prediksi & Coefficient & Prob. \\
\hline C & & 0.755 & 0.0717 & ACCRUAL & + & -0.0012 & 0.1207 \\
DO & H2a: - & -1.153 & 0.1214 & ROA & - & 0.0072 & 0.1033 \\
SI & H2b: - & -0.0863 & 0.163 & OCF & + & 0.0827 & $0.0861^{*}$ \\
SIZE & - & 0.0081 & $0.0038^{* * *}$ & GDP & - & -0.031 & $0.0490^{* *}$ \\
BM & + & 0.0164 & 0.2909 & DINV & - & -0.0511 & $0.0054^{* * *}$ \\
\hline R-squared & & & & & & 0.0313 \\
Adjusted Rsquared & & & & & & 0.0256 \\
\multicolumn{2}{l}{$\begin{array}{l}\text { Prob(F-statistic) } \\
\text { r }\end{array}$} & & & & & & $0.0000^{* * *}$ \\
\hline
\end{tabular}

Tabel 4. Hasil Pengujian Hipotesis 3

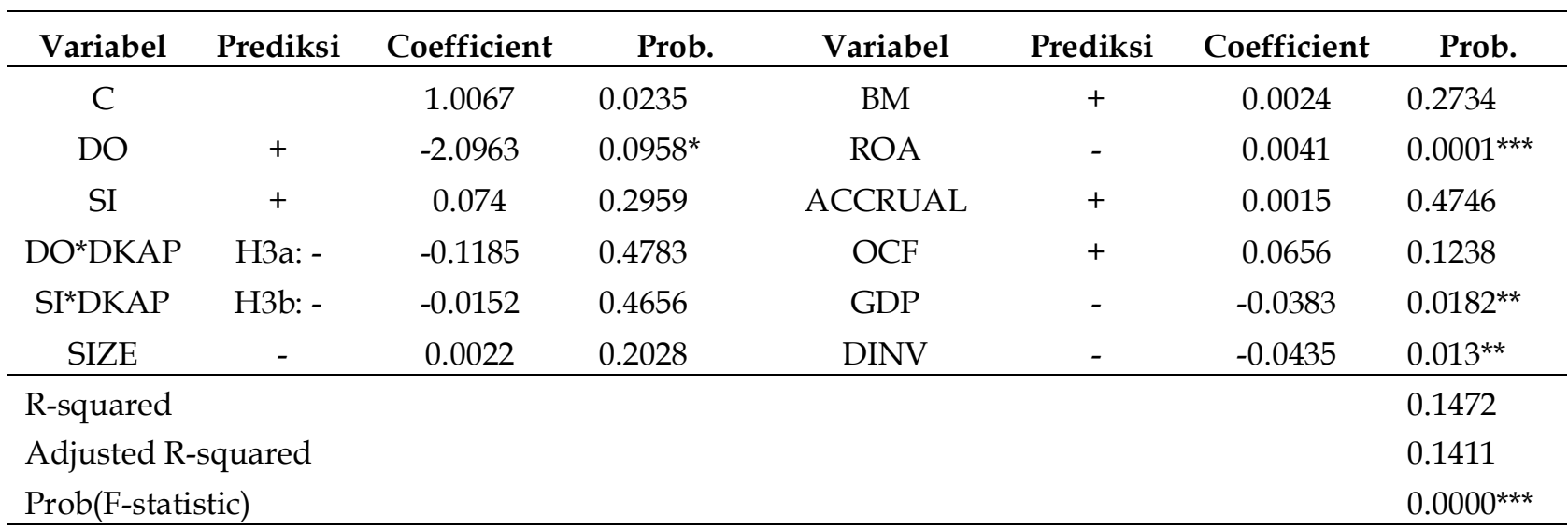

Tabel 5. Hasil Pengujian Hipotesis 4

\begin{tabular}{ccclcccc}
\hline Variabel & Prediksi & Coefficient & Prob. & Variabel & Prediksi & Coefficient & Prob. \\
\hline C & & 0.7906 & 0.0614 & BM & + & 0.0069 & 0.1113 \\
DO & + & -2.2472 & $0.0433^{* *}$ & ROA & - & -0.0012 & 0.1156 \\
SI & + & -0.0490 & 0.3202 & ACCRUAL & + & 0.0075 & 0.4022 \\
DO*DKAP & H4a: - & 3.3045 & $0.0212^{* *}$ & OCF & + & 0.0760 & 0.1074 \\
SI DKAP & H4b: - & -0.0569 & 0.3521 & GDP & - & -0.032 & $0.0426^{* *}$ \\
SIZE & - & 0.0077 & $0.0044^{* * *}$ & DINV & - & -0.0547 & $0.0031^{* * *}$ \\
\hline R-squared & & & & & & & 0.0471 \\
Adjusted R-squared & & & & & & 0.0403 \\
Prob(F-statistic) & & & & & & & $0.0000^{* * *}$ \\
\hline
\end{tabular}




\section{Hasil Pengujian Hipotesis 4}

Berdasarkan hasil regresi maka hipotesis $4 a$ tidak diterima karena hasil pengujian menunjukkan bahwa kualitas audit memperkuat pengaruh negatif operasi yang dihentikan terhadap unexpected change in core earnings. Adanya pengaruh negatif operasi yang dihentikan terhadap unexpected change in core earnings bukan merupakan classification shifting karena sudah dibuktikan melalui hipotesis 2 . Hipotesis $4 \mathrm{~b}$ ditolak karena $p$-value $>10 \%$, hal ini berarti bahwa kualitas audit yang diproksikan dengan KAP big 4 dan KAP non-big 4 tidak dapat memoderasi pengaruh negatif special items tahun ini terhadap unexpected change in core earnings tahun berikutnya.

\section{PEMBAHASAN}

Hasil pengujian hipotesis 1a ditolak dan hasil ini berbeda dengan penelitian Barua et al. (2010). Hal ini kemungkinan dikarenakan negara-negara yang dijadikan sampel dalam penelitian ini sudah menerapkan IFRS No.5 mengenai penyajian dan pengungkapan operasi yang dihentikan dan aset yang tersedia untuk dijual sehingga classification shifting menjadi lebih sulit untuk dilakukan.

IFRS No.5 ini menjadikan laporan keuangan lebih transparan dan memberikan lebih banyak aturan mengenai pengungkapan dan pedoman yang lebih spesifik mengenai penyajian operasi yang dihentikan (Athanaskou et al., 2008). Sejalan dengan pengujian tambahan yang dilakukan Barua et al. (2010), classification shifting melalui operasi yang dihentikan menjadi lebih sulit untuk dilakukan karena IFRS mewajibkan pengungkapan secara mendetail untuk operasi yang dihentikan (Aitken, 2011). IFRS diharapkan dapat membuat laporan keuangan menjadi lebih bermanfaat bagi penggunanya karena dapat mengurangi asimetri informasi sehingga investor dapat mengambil keputusan yang lebih baik. Hal tersebut juga diharapkan dapat memberi sinyal kepada analis dan investor bahwa perusahaan tidak melakukan classifcation shifting (Aitken, 2011).

Hipotesis 1b juga ditolak, yaitu tidak ditemukan indikasi adanya classification shifting melalui special items. Hasil penelitian ini sejalan dengan Athanasakou et al. (2009) yang memberikan bukti empiris bahwa classification shifting dengan menggeser core earnings ke non-reccuring items bukan merupakan common practice di UK. Hal ini dikarenakan penerapan IAS 1 yang sejalan dengan FRS 3 Reporting Financial Performance di UK yang mewajibkan perusahaan untuk melaporkan laba bersih per saham dan membagi laba tersebut ke dalam core dan transitory earnings untuk meningkatkan transparansi pengungkapan laporan keuangan yang membatasi kemungkinan terjadinya classification shifting, dan hal ini juga dapat meningkatkan kemungkinan bahwa investor dapat mendeteksi kesalahan pengklasifikasian non-recurring items (Athanasakou et al., 2009).

Hipotesis $2 \mathrm{a}$ dan $2 \mathrm{~b}$ juga ditolak, ini juga dapat dikarenakan classification shifting mungkin terjadi pada tahun $t+1$ yang menyebabkan hasil pengujian hipotesis kedua tidak signifikan karena ada kemungkinan terjadi classification shifting yang beruntun yaitu pada tahun $t$ dan $t+1$ yang berada di luar periode penelitian ini.

Hipotesis 3a dan 3b ditolak, hal ini berarti bahwa kualitas audit tidak terbukti dapat mengurangi/menghambat terjadinya classification shifting . Hasil ini kemungkinan dikarenakan hasil pengujian hipotesis sebelumnya tidak terbukti ditemukan adanya classification shifting sehingga pengujian $\mathrm{H} 3$ tidak dapat membuktikan pengaruh kualitas audit terhadap classification shifting. Menurut Yasar (2011) adanya perbedaan hasil antara penelitian di Turki, Korea, dan Yunani dengan penelitian di U.S dan negara maju lainnya kemungkinan dikarenakan adanya perbedaan audit dan mekanisme pengawasan seperti adanya risiko hukum yang lemah terhadap auditor, dan mekanisme pemberian penalti kepada auditor belum sepenuhnya 
dilaksanakan dan tidak memberikan efek jera. Selain itu, ditolaknya hipotesis ketiga dapat dikarenakan proksi kualitas audit yang digunakan dalam penelitian ini mungkin kurang cocok digunakan untuk negara-negara ASEAN. Kwon et al. (2007) mengatakan bahwa ukuran KAP tidak cocok digunakan sebagai proksi kualitas audit pada negara-negara yang memiliki sistem penegakan hukum yang lemah, proksi kualitas audit yang baik untuk negara dengan sistem penegakan hukum lemah adalah spesialisasi auditor. Mayoritas negara yang menjadi sampel dalam penelitian memiliki sistem penegakan hukum yang lemah sehingga ukuran KAP yang dijadikan proksi kualitas audit kurang cocok digunakan dalam penelitian ini.

Penolakan hasil pengujian hipotesis 4a dan $4 \mathrm{~b}$ memperkuat hasil pengujian hipotesis kedua bahwa peningkatan unexpected core earnings bukan disebabkan adanya classification shifting melainkan real economic improvement. Hasil ini juga dapat disebabkan karena pengujian hipotesis sebelumnya juga ditolak yang berarti tidak ditemukannya classification shifting sehingga kualitas audit juga tidak ditemukan dapat mengurangi atau menghambat classification shifting.

\section{KESIMPULAN}

Dari pengujian yang telah dilakukan dapat diambil kesimpulan bahwa:

- Pada negara Malaysia, Singapura, Indonesia dan Filiphina tidak ditemukan adanya praktik manajemen laba melalui classification shifting. Hal ini kemungkinan dikarenakan negaranegara yang dijadikan sampel dalam penelitian ini sudah menerapkan IFRS No. 5.

- Kualitas audit tidak terbukti dapat mengurangi terjadinya praktik manajemen laba melalui classification shifting dikarenakan tidak ditemukannya pengaruh positif operasi yang dihentikan dan special items terhadap unexpected core earn- ings yang berarti tidak terjadi manajemen laba melalui classification shifting.

\section{SARAN}

Adapun beberapa keterbatasan dalam penelitian ini diantaranya:

- Penelitian selanjutnya diharapkan dapat memperbanyak sampel penelitian agar memberikan hasil yang lebih tepat serta dapat menggambarkan kondisi di negara-negara ASEAN.

- Penelitian selanjutnya diharapkan menggunakan periode sebelum dan sesudah penerapan IFRS no. 5 sehingga dapat memperbandingkan kondisi terjadinya praktik manajemen laba melalui classification shifting sebelum dan sesudah penerapan IFRS No. 5 .

- Menggunakan spesialisasi auditor sebagai proksi dari kualitas audit.

- Memasukkan variabel operasi yang dihentikan $\left(\mathrm{DO}_{\mathrm{t}+1}\right)$ dan special items $\left(\mathrm{SI}_{\mathrm{t}+1}\right)$ tahun berikutnya sebagai variabel kontrol pada pengujian hipotesis 2 untuk mengurangi dampak terjadinya classification shifting pada tahun berikutnya.

\section{DAFTAR PUSTAKA}

Aitken, K. 2011. Classification Shifting Under IFRS. University of Waterloo. Research Paper.

Anantharaman, D., Darrough, M., dan Lee, Y. G. 2014. Classification Shifting within Non-Reccuring Items. Working Paper.

Athanasakou, V.E., Strong, N.C., dan Walker, M. 2009. Earnings management or forecast guidance to meet analyst expectation?. Accounting and Business Research. Vol. 39 No. 1 Page. 3-35.

Barua, A., Lin, S., dan Sbaraglia, A.M. 2010. Earnings Management Using Discontinued Operations. The Accounting Review. Vol. 85 No.5 Page 1485-1509.

Becker et al. 1998. The Effect of Audit Quality on Earnings Management. Contemporary Accounting Research. Vol.15 No.1 Page. 1-24. 


\section{Jurnal Keuangan dan Perbankan | KEUANGAN}

Vol. 20, No.2, Mei 2016: 186- 194

Fan, Y., Barua, A., Cready, W.M., dan Thomas, W.B. Managing Earnings Using Classification Shifting: Evidence from Quarterly Special Items. The Accounting Review. Vol. 85 No. 4 Page. 1303-1323.

Herusetya, Antonius. 2012. Analisis Audit Quality Metric Score (AQMS) sebagai Pengukur Multidimensi Kualitas Audit terhadap Manajemen Laba dan Kandungan Informasi Laba. Disertasi Universitas Indonesia.

Kwon, S.Y., Lim, C.Y., dan Siang Tan, P.M. 2007. Legal Systems and Earnings Quality: The Role of Auditor Industry Specialization. A Journal of Practice $\mathcal{E}$ Theory. Vol.26 No.2 Page. 25-55.

Mc Vay, S.E. 2006. Earnings Management Using Classification Shifting: An Examination of Core Earnings and Special Items. The Accounting Review. Vol. 81 No.3 Page 501-531.
Tendelo, B. V., dan Vanstraelen, A. 2008. Earnings Management and Audit Quality in Europe: Evidence from the Private Client Segment Market. European Accounting Review. Vol. 17 No. 3 page 447-469.

Wardhani. Ratna. 2009. Pengaruh Proteksi bagi Investor, Konvergensi Standar Akuntansi, Implementasi Corporate Governance, dan Kualitas Audit terhadap Kualitas Laba: Analisis Lintas Negara di Asia. Disertasi Universitas Indonesia.

Wulandari, S., dan Kusuma, I.S. 2011. Mendeteksi Managemen Laba dengan menggunakan Classification Shifting: Pengujian Core Earnings dan Extraordinary Items (Studi Empiris di NegaraNegara ASEAN). Simposium Nasional Akuntansi XIV Aceh.

Yasar, Alpaslan. 2013. Big Four Auditors' Audit Quality and Earnings Management Turkish Stock Market. International Journal of Business and Social Science. Vol.4 No.17. 